\title{
PTPRM, a candidate tumor suppressor gene in small intestinal neuroendocrine tumors
}

\author{
Elham Barazeghi, Per Hellman, Gunnar Westin and Peter Stålberg \\ Department of Surgical Sciences, Uppsala University, Uppsala University Hospital, Rudbeck Laboratory, Uppsala, Sweden
}

Correspondence should be addressed to E Barazeghi or P Stålberg: elham.barazeghi@surgsci.uu.se or peter.stalberg@surgsci.uu.se

\begin{abstract}
Small intestinal neuroendocrine tumors (SI-NETs) are small, slow growing neoplasms with loss of one copy of chromosome 18 as a common event. Frequently mutated genes on chromosome 18 or elsewhere have not been found so far. The aim of this study was to investigate a possible tumor suppressor role of the transmembrane receptor type tyrosine phosphatase PTP $\mu$ (PTPRM at 18p11) in SI-NETs. Immunohistochemistry, quantitative RT-PCR, colony formation assay and quantitative CpG methylation analysis by pyrosequencing were performed. Undetectable/very low levels of PTPRM or aberrant pattern of immunostaining, with both negative and positive areas, were detected in the majority of tumors (33/40), and a significantly reduced mRNA expression in metastases compared to primary tumors was observed. Both the DNA methylation inhibitor 5-aza-2'deoxycytidine and the S-adenosylhomocysteine hydrolase inhibitor 3-deazaneplanocin A (DZNep) induced PTPRM expression in CNDT2.5 and KRJ-I SI-NET cells. CPG methylation of upstream regulatory regions, the promoter region and the exon 1/intron 1 boundary was detected by pyrosequencing analysis of the two cell lines and not in the analyzed SI-NETs. Overexpression of PTPRM in the SI-NET cell lines reduced cell growth and cell proliferation and induced apoptosis. The tyrosine phosphatase activity of PTPRM was not involved in cell growth inhibition. The results support a role for PTPRM as a dysregulated candidate tumor suppressor gene in SI-NETs and further analyses of the involved mechanisms are warranted.
\end{abstract}

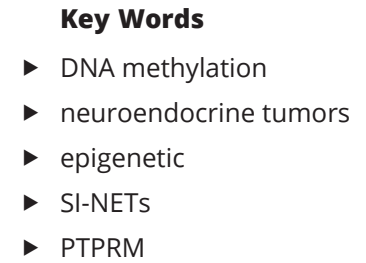

Endocrine Connections (2019) 8, 1126-1135

\section{Introduction}

Small intestinal neuroendocrine tumors (SI-NETs) arise from enterochromaffin cells in the gastrointestinal tract, which are small and slow-growing (Ki67 proliferation index is often $<2 \%$ ) tumors with annual incidence of 1 per 100,000, but still the majority of patients are asymptomatic and have tumor spread to regional lymph nodes and liver at the time of diagnosis, with a 5-year survival rate of $65 \%$. These tumors can produce hormones such as serotonin and tachykinins, which can give rise to carcinoid syndrome as a major cause of morbidity and mortality in approximately $20 \%$ of SI-NET patients.

To date, genetic and epigenetic alterations in SI-NETs are poorly studied. Massive DNA sequencing analysis on
SI-NETs revealed that these tumors are quite stable with no recurrent mutations (1). Loss of one copy of chromosome 18 is the most prevalent in SI-NETs (60-90\%) $(2,3)$, and pathogenic mutations at the CDKN1B locus on chromosome 12 encoding p27 have been found in 8\% of tumors (4). Promoter DNA methylation studies revealed increased RASSF1A/CTNNB1 methylation associated with metastatic progression, and epigenetic repression of TCEB3C in SI-NETs $(5,6)$. A comprehensive integrated molecular analysis of a large cohort of SI-NETs revealed that these tumors are highly epigenetically dysregulated $(7,8,9)$.

Chromosomal loss is a frequent event in malignant tumors that can lead to the identification of https://ec.bioscientifica.com https://doi.org/10.1530/EC-19-0279 (c) 2018 The authors Published by Bioscientifica Ltd
This work is licensed under a Creative Commons Attribution-NonCommercial-NoDerivatives 4.0 enternationab ticense.ifica.com at 04/26/2023 09:11:33AM 
tumor suppressor genes, but sequencing analysis of genes located on chromosome 18 failed to reveal recurrent mutations in SI-NETs, which may have implications for epigenetic silencing as driver mechanisms in this region $(2,3)$. Transmembrane receptor type tyrosine phosphatases have been found frequently mutated in various types of cancers and may have important roles in acting as tumor suppressor genes in tumorigenesis. A candidate tumor suppressor gene on chromosome 18 p11.2 is protein tyrosine phosphatase, receptor type $\mathrm{M}$ (PTPRM or PTP $\mu$ ) that regulates many processes, such as cell differentiation and proliferation, apoptosis, adhesion and motility, through dephosphorylation of multiple proteins in signaling pathways. PTPRM is a homophilic cell-adhesion molecule, involved in cell-cell adhesion and mediates cell-cell aggregation through interaction with other subfamily members. PTPRM has been shown to be frequently hypermethylated at the promoter in acute lymphoblastic leukemia (10), and downregulation of PTPRM due to aberrant DNA promoter hypermethylation and loss of heterozygosity, with a putative tumorsuppressive role of PTPRM, was demonstrated in colorectal cancer $(11,12)$. PTPRM has been shown to have a crucial role in epidermal growth factor receptor signaling, and downregulation of PTPRM increased cell migration in human airway epithelia and gliomas $(13,14)$.

In this study, we investigated a possible role of PTPRM in small intestinal neuroendocrine tumorigenesis, and whether epigenetic mechanisms are involved in regulation of its expression.

\section{Materials and methods}

\section{Tissue specimens}

In total 51 tumors and 3 small intestinal tissue specimens were included in the study, from 24 patients (Supplementary Table 1, see section on supplementary data given at the end of this article) that were diagnosed with SI-NET and operated upon in Uppsala University Hospital. Twenty-three primary tumors, 21 mesenteric, 6 liver, and 1 extramesenteric lymph node metastases and 3 'normal' small intestine tissue specimens were analyzed. Informed consent and approval of the Uppsala Local Ethical Committee were achieved. Two human SI-NET cell lines, CNDT2.5 (adhesive cells) $(15,16)$ and KRJ-I (suspension cells) $(17,18,19)$ were used in the experiments. Both SI-NET cell lines expressed the neuroendocrine cell marker synaptophysin (20).

\section{Immunostaining}

Paraffin-embedded tumor sections were passed through descending alcohol concentrations to distilled water and background staining was blocked with 3\% hydrogen peroxide. Then, the sections were heated in citrate buffer $\mathrm{pH} 6.0$ and were treated with the proper normal serum and the goat polyclonal anti-PTPRM antibody (ab111207, Abcam), the rabbit polyclonal anti-PTPRM antibody (raised against amino acids 791-870 mapping within an internal region of PTPRM of human origin, sc-25433, Santa Cruz Biotechnology) or the rabbit monoclonal anti-synaptophysin antibody (ab32127, Abcam). After incubation with proper secondary antibody and $\mathrm{ABC}$ complex, DAB was used for visualization. Consecutive tissue sections of intestinal mucosa were stained with the anti-PTPRM antibody (ab111207, Abcam) or a mouse monoclonal anti-chromogranin A antibody (LK2H10, Thermo Fisher Scientific) as mentioned above. Immunofluorescence: The sections were treated and incubated with anti-chromogranin A antibody as mentioned above, followed by incubation with the proper fluorescence secondary antibody (Alexa 488, Life Technologies). Sections were washed three times with PBS (0.05\% Tween 20$)$ and incubated with the antiPTPRM antibody (ab111207, Abcam). Then, sections were incubated with the fluorescence secondary antibody (Alexa 568, Life Technologies), washed again and mounted with Vectashield with DAPI (Vector Laboratories).

\section{RNA extraction and quantitative RT-PCR analysis}

Total RNA was extracted from cryosections of fresh frozen tumor tissues or cultured cells using RNeasy Plus Mini kit (Qiagen) according to the manufacturer's instruction. Hematoxylin-eosin staining of the frozen sections was used to select specimens with at least $80 \%$ tumor cells. Extracted RNA was treated with DNase I using TURBO DNA-free kit (Life Technologies). Successful treatment of all RNA preparations was established by PCR analysis. The 'First strand cDNA Synthesis kit' (Thermo Fisher Scientific) was applied for cDNA synthesis with random hexamer primers, according to the manufacturer's instructions. qRT-PCR was performed on StepOnePlus Real-Time PCR systems (Life Technologies Corporation) using TaqMan gene expression Master Mix and assays for PTPRM (Hs00267809_m1), GAPDH (Hs02758991_g1) and 18S rRNA (Hs03928990_g1) transcripts. All samples were amplified in triplicates. Puromycin- $N$ acetyltransferase gene (pac) expression analysis was

This work is licensed under a Creative Commons Attribution-NonCommercial-NoDerivatives 4.0 enternationad ticense ifica.com at 04/26/2023 09:11:33AM 
performed on Stratagene Mx3005P real-time PCR system (Agilent Technologies) using iQ SYBR Green Supermix (Bio-Rad) and primers 5'-TGCAAGAACTCTTCCTCACG and 5'-AGGCCTTCCATCTGTTGCT.

\section{Immunoprecipitation and Western blotting analysis}

Protein extracts from cultured cells prepared using radio immunoprecipitation assay buffer (RIPA buffer) (sc-24948, Santa Cruz Biotechnology) according to the manufacturer's instructions. The total protein extracts were incubated with $2 \mu \mathrm{g}$ mouse monoclonal anti-PTPRM antibody (ab30321, Abcam) and incubated overnight at $4^{\circ} \mathrm{C}$ with rotation. $20 \mu 1$ of protein A/G PLUS-Agarose immunoprecipitation reagent (sc-2003, Santa Cruz Biotechnology) was added to each sample and incubated $3 \mathrm{~h}$ at $4^{\circ} \mathrm{C}$ with rotation. Beads were collected by centrifugation at $1000 \mathrm{~g}$ for $5 \mathrm{~min}$ at $4^{\circ} \mathrm{C}$, and washed three times with $1.0 \mathrm{ml}$ ice cold RIPA buffer. Proteins were eluted from the beads with $30 \mu \mathrm{L}$ of $2 \times$ Laemmli buffer (Bio-Rad), heated for $5 \mathrm{~min}$ at $95^{\circ} \mathrm{C}$ and subjected to Western blotting analysis. The anti-PTPRM antibody (ab30321, Abcam) and goat polyclonal antiActin (sc-1616, Santa Cruz Biotechnology) were used. After incubation with the proper secondary antibody, bands were visualized using the enhanced chemiluminescence system (GE Healthcare).

\section{Bisulfite treatment and pyrosequencing}

Genomic DNA was extracted from frozen tissue using DNeasy Blood and tissue kit (Qiagen), and bisulfite treated using EpiTect bisulfite kit (Qiagen) according to the manufacturer's instructions. Methylation status for $13 \mathrm{CpGs}$ in the PTPRM promoter region, $25 \mathrm{CpGs}$ in the exon 1/intron 1 region and 6 out of the 8 CpGs located at the CGI shores upstream of the PTPRM transcription start site (TSS700-1600) were measured by quantitative pyrosequencing. PCR and sequencing primers are listed in Supplementary Table 2. The PCR included MyTaq HS Mix (Bioline USA, Taunton, MA, USA), $10 \mathrm{pmol}$ of each primer and bisulfite-treated DNA as template. Pyrosequencing was performed using $10 \mu \mathrm{L}$ PCR product with the PyroMark Q24 system (Qiagen) according to the manufacturer's instructions.

\section{Cell transfection and drug treatment}

CNDT2.5 cells $\left(2 \times 10^{5}\right)$ were distributed onto six-well plates and transfected in triplicates with $4 \mu \mathrm{g}$ PTPRM expression vector (ViGene) or empty vector (pEnter), using $8 \mu \mathrm{L}$ Lipofectamin 2000 transfection reagent (Life Technologies), according to the manufacturer's instructions. After $6 \mathrm{~h}$, fresh medium, complemented with $0.5 \mu \mathrm{g} / \mathrm{mL}$ puromycin (Invivogene) was added. KRJ-I cells $\left(1 \times 10^{5}\right)$ were seeded onto 12 -well plates prior to transfection and were transfected in triplicates with $0.4 \mu \mathrm{g}$ PTPRM expression vector (ViGene) or empty vector (pEnter) using $1.5 \mu \mathrm{L}$ Attractene transfection reagent (Qiagen) according to the manufacturer's instructions. Successful transfections were monitored with quantitative RT-PCR after $72 \mathrm{~h}$. CNDT2.5 cells were transfected with PTPRM wild type (wt) and mutant (mut) expression vectors (11) or empty vector (pcDNA3.1) as mentioned above, and fresh medium complemented with $0.2 \mathrm{mg} / \mathrm{ml}$ G418 (Sigma Aldrich) was added after $6 \mathrm{~h}$.

CNDT2.5 $\left(2 \times 10^{5}\right)$ and KRJ-I $\left(1 \times 10^{5}\right)$ cells were treated with $10 \mu \mathrm{M}$ and $5 \mu \mathrm{M}$ of the global hypomethylating agent, 5-aza-2'-deoxycytidine (Sigma Aldrich), respectively, or with $10 \mu \mathrm{M}$ of the S-adenosylhomocysteine hydrolase inhibitor 3-deazaneplanocin A (DZNep, Merck) for $72 \mathrm{~h}$. Fresh medium with additions was added every $24 \mathrm{~h}$.

\section{Colony formation assay}

CNDT2.5 cells $\left(2 \times 10^{5}\right)$ were seeded onto six-well plates and transfected in triplicates with PTPRM expression vector or empty vector (pEnter) as described above. $24 \mathrm{~h}$ after transfection, 2000 cells were distributed onto six-well plates, and fresh medium with $0.5 \mu \mathrm{g} / \mathrm{mL}$ puromycin was added every $72 \mathrm{~h}$. After 10 days in puromycin selection, the cells were fixed with $10 \%$ acetic acid/10\% methanol and stained with $0.4 \%$ crystal violet, and the visible colonies were counted. Colony formation assay was also performed with PTPRM - (wt) and (mut) expression vectors (11) or empty vector (pcDNA3.1) as described earlier, and fresh medium with $0.2 \mathrm{mg} / \mathrm{mL} \mathrm{G418}$ was added every $72 \mathrm{~h}$. The two mutations in PTPRM-mut, Cys ${ }^{1095} \mathrm{Ser}$ and $\mathrm{Cys}^{1389} \mathrm{Ser}$, were confirmed by DNA sequencing using primers 5'-GACCTAACTTGGGAAGCAGGC and 5'-TAGAAGGCACAGTCGAGG (data not shown).

\section{Cell proliferation assay and apoptosis}

CNDT2.5 $\left(2 \times 10^{5}\right)$ and KRJ-I $\left(1 \times 10^{5}\right)$ cells were transfected with PTPRM expression vector (ViGene) or empty vector (pEnter) as described earlier, and after $72 \mathrm{~h}$, the same number of cells for all the samples were distributed in a 96-well plate and cell proliferation was followed for $24 \mathrm{~h}$. Then, cell proliferation was 
measured by the CyQUANT cell proliferation assay kit (Invitrogen, Thermo Fisher Scientific) according to the manufacturer's instruction. The cells were stained with CyQuant GR dye solution and fluorescence intensity was measured at $480 / 520 \mathrm{~nm}$ using Infinite $200 \mathrm{PRO}$ (TECAN) plate reader. The Cell Death Detection ELISA kit (Roche Molecular Biochemicals) was used to measure apoptosis, as determined by quantifying cytoplasmic histone-associated-DNA-fragments, $72 \mathrm{~h}$ after transfection according to the manufacturer's protocol. As a positive control, CNDT2.5 and KRJ-I cells were incubated with $0.1 \mu \mathrm{g} / \mathrm{mL}$ camptothecin (Sigma Aldrich) for $48 \mathrm{~h}$ and the reported values were calculated as a ratio of value/positive control (camptothecin) $\times 100$.

CNDT2.5 $\left(2 \times 10^{5}\right)$ and KRJ-I $\left(1 \times 10^{5}\right)$ cells were treated with the 5-aza-2'-deoxycytidine or the 3-deazaneplanocin A (DZNep, Merck) as described earlier. After $72 \mathrm{~h}$, cell proliferation and apoptosis were measured as mentioned above.

\section{Statistical analysis}

Wilcoxon-Mann-Whitney $U$ test was used to calculate differences in PTPRM mRNA expression between primary tumors and metastases. Differences in realtime quantitative RT-PCR, CpG methylation, colony formation assay, proliferation and apoptosis were evaluated using unpaired $t$ test. ANOVA test was used to calculate differences between three biological groups, and Bonferroni test was used to adjust the $P$ values. Data are presented as mean \pm s.D. and $P<0.05$ was considered significant. Statistical analysis was performed using $\mathrm{R}$ version 3.2.3 (2015-12-10).

\section{Results}

\section{PTPRM is frequently downregulated in SI-NETs}

Immunohistochemical analysis was performed in 19 primary tumors and 21 paired metastases (Fig. 1 and Supplementary Table 3). PTPRM protein expression was undetectable or very low in 15 tumors out of 40 (4 primary and 11 metastases), and variable heterogeneous pattern of staining $(\mathrm{VH})$, with both negative and positive areas, was observed in 18 tumors (12 primary and 6 metastases). Seven tumors, 3 primary and 4 metastases, displayed overall positive staining regardless of strength. The staining for PTPRM in both primary tumors and metastases was cytoplasmic or cytoplasmic/nuclear (Supplementary Table 3). Out of 25 tumors with either $\mathrm{VH}$ or positive pattern of staining, 10 tumors showed only cytoplasmic staining. In the remaining 15 tumors, cytoplasmic/nuclear staining was observed. All tumors were stained with an additional anti-PTPRM antibody, and overall, the same pattern of staining was observed (Supplementary Fig. 1A). Tumors with negative PTPRM staining, stained positive for synaptophysin (Supplementary Fig. 1B). No staining was observed in the absence of the primary antibody, and chromogranin A-positive cells in the normal small intestine stained positive for PTPRM (Fig. 2A and B). These cells likely represent the enterochromaffin cell of origin of SI-NETs.

PTPRM mRNA expression analysis revealed overall very low but significantly reduced expression of PTPRM in metastatic tumors $(n=27)$ compared to the paired primary tumors $(n=23)$, as determined by quantitative RT-PCR (Fig. 3). Thus, the results demonstrated frequent downregulation of PTPRM in the analyzed SI-NETs.
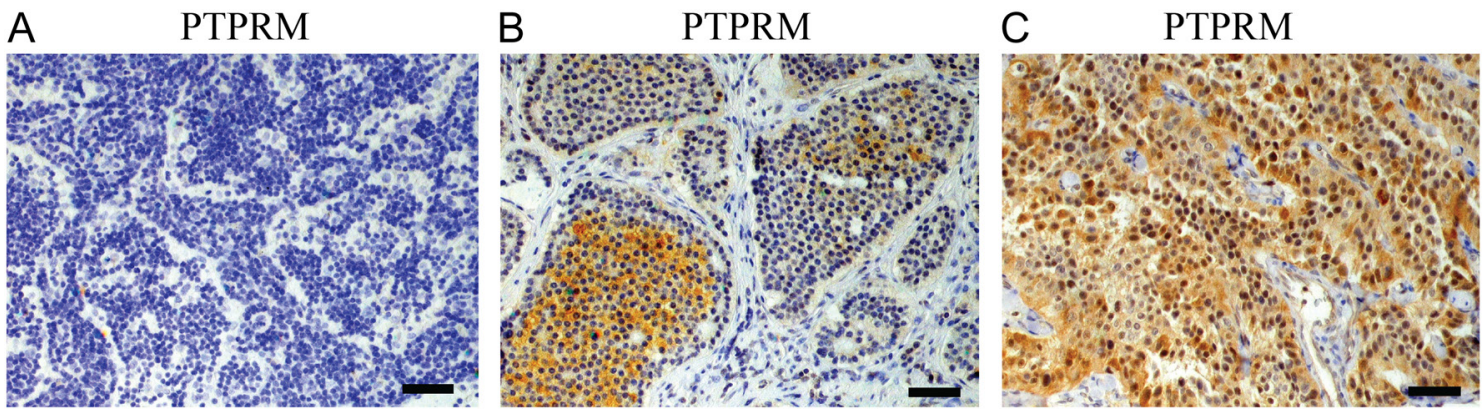

\section{Figure 1}

Representative results from immunohistochemical analysis of PTPRM (anti-PTPRM antibody ab111207) in 19 primary tumors and 21 paired metastases. Scale bar, $50 \mu \mathrm{m}$. (A) Negative staining of a metastatic tumor, (B) variable heterogeneous pattern of staining, with both negative and positive areas, in a primary tumor and (C) positive staining of a metastatic tumor are shown.

https://ec.bioscientifica.com https://doi.org/10.1530/EC-19-0279 (c) 2019 The authors Published by Bioscientifica Ltd

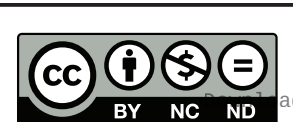

This work is licensed under a Creative Commons Attribution-NonCommercial-NoDerivatives 4.0 Internationab bicense.ifica. com at 04/26/2023 09:11:33AM 
A

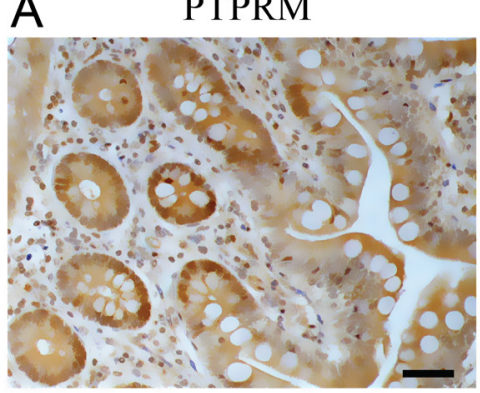

B

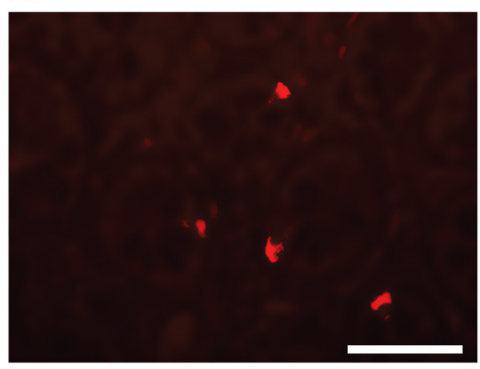

Chromogranin A

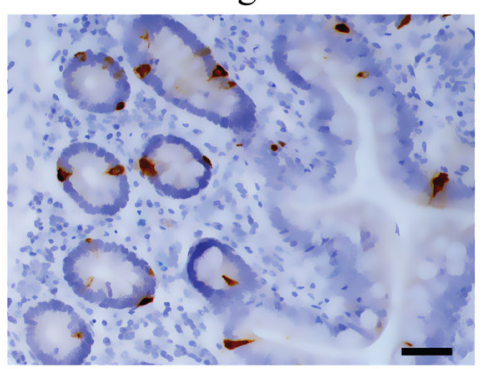

Chromogranin A

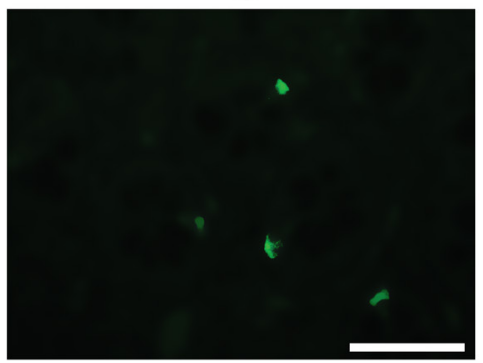

No primary antibody

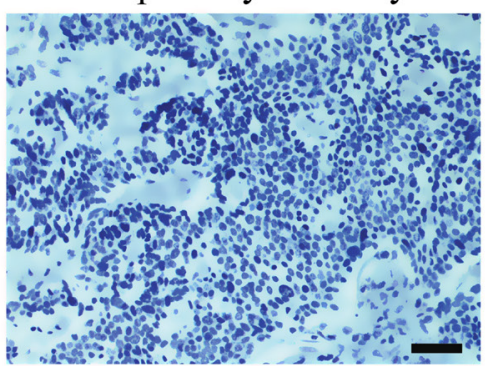

Merge

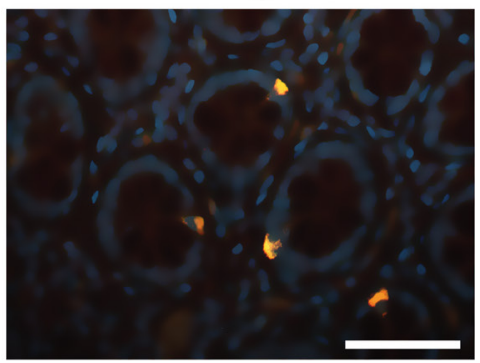

Figure 2

Chromogranin A-positive cells are positively stained for PTPRM in normal small intestinal tissue. (A) Two consecutive tissue sections of the normal small intestine were used for immunohistochemical analysis of Chromogranin A and PTPRM. PTPRM staining was observed only in the presence of the primary antibody (No primary antibody). Scale bar, $50 \mu \mathrm{m}$. (B) Immunofluorescent double staining for chromogranin A and PTPRM. Scale bar, $50 \mu \mathrm{m}$.

\section{Epigenetic inactivation of PTPRM in SI-NETs}

In order to investigate whether PTPRM expression was epigenetically suppressed in SI-NET cells, the SI-NET cell lines CNDT2.5 and KRJ-I were treated with the DNA methylation inhibitor 5-aza-2'-deoxycytidine (Aza). This resulted in more than a 100-fold increased expression of PTPRM in CNDT2.5 cells and a less prominent effect in KRJ-I cells (Fig. 4A). Also treatment with the S-adenosylhomocysteine hydrolase inhibitor 3-deazaneplanocin A (DZNep) induced mRNA expression of PTPRM approximately 10-fold in CNDT2.5 cells and 5-fold in KRJ-I cells (Fig. 4B). Both Aza and DZNep treatment of the cells reduced cell proliferation and induced apoptosis in CNDT2.5- and KRJ-I-treated cells compared to the control cells (Supplementary Fig. 2A and B).

Next, we examined the methylation profile of the PTPRM upstream regulatory region which contains a CpG island (CGI) spanning the promoter, exon 1 and part of intron 1 (Fig. 5A). The PTPRM gene has been shown to be methylated at the exon 1 /intron 1 boundary in colon cancer (11). Therefore, by performing quantitative bisulfite pyrosequencing, $13 \mathrm{CpG}$ sites at the promoter region and $25 \mathrm{CpG}$ sites at the exon 1/intron 1 region were analyzed for methylation in primary tumors, paired metastases and both SI-NET cell lines. All tumors showed very low levels of methylation $(<10 \%)$, while CpG sites in CNDT2.5 cells were highly methylated (90\%), and KRJ-I cells demonstrated moderate levels of methylation (30-40\%) (Fig. 5B, C and Supplementary Table 4).

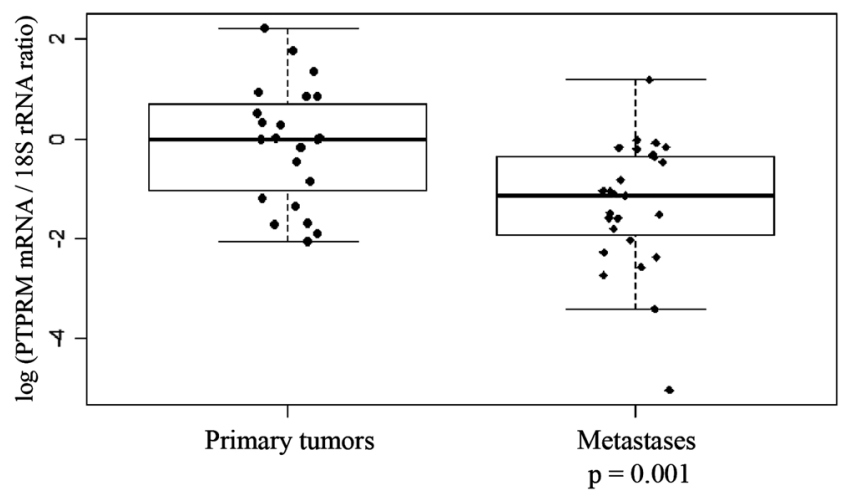

Figure 3

Expression level of PTPRM in primary tumors and metastases (logarithmic scale). Real-time RT-PCR analysis of PTPRM shows significantly reduced expression in metastases $(n=27)$ compared to paired primary tumors $(n=23)$. Wilcoxon-Mann-Whitney $U$ test result displayed in box plot $(P=0.001)$. Whiskers show minimum and maximum values, boxes represent $25-75 \%$ data ranges and horizontal lines within boxes are medians. (Primary tumors: lower quartile $=-1.1$, median $=0$, upper quartile $=0.69)$, (Metastases: lower quartile $=-2$, median $=-1.2$, upper quartile $=-0.35$ ). (Wilcoxon-Mann-Whitney $U$ test without outliers; Primary tumors $(n=20)$ and metastases $(n=26), P=0.002)$.
This work is licensed under a Creative Commons Attribution-NonCommercial-NoDerivatives 4.0 elnternationab ticense.ifica.com at 04/26/2023 09:11:33AM 
A $\quad$ CNDT2.5

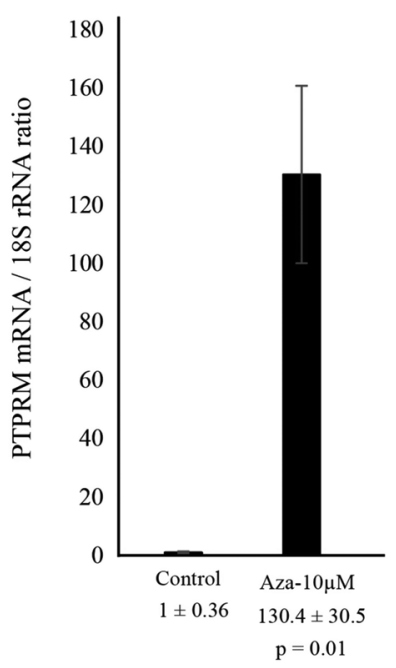

B $\quad$ CNDT2.5

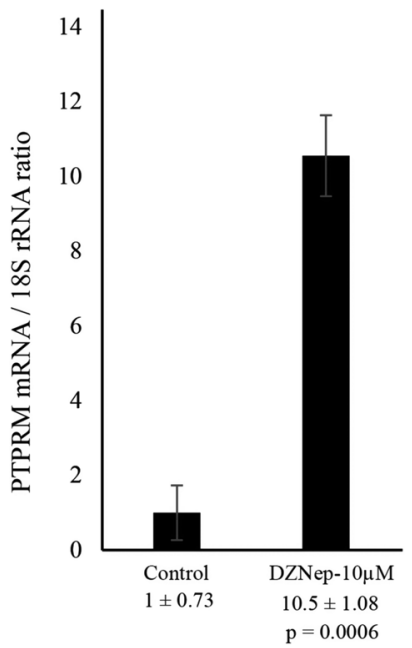

KRJ-I

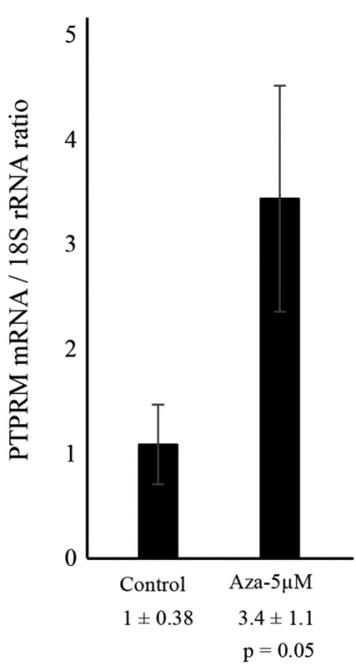

KRJ-I

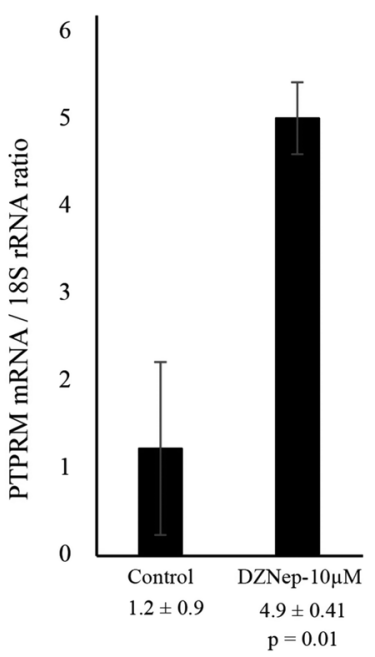

A

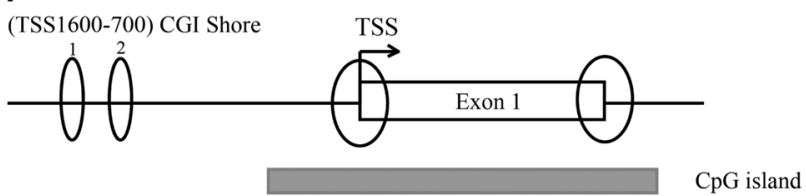

B

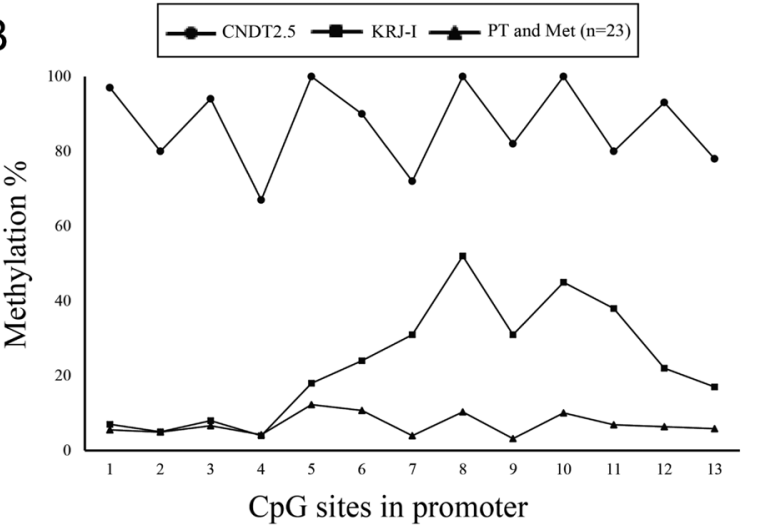

C
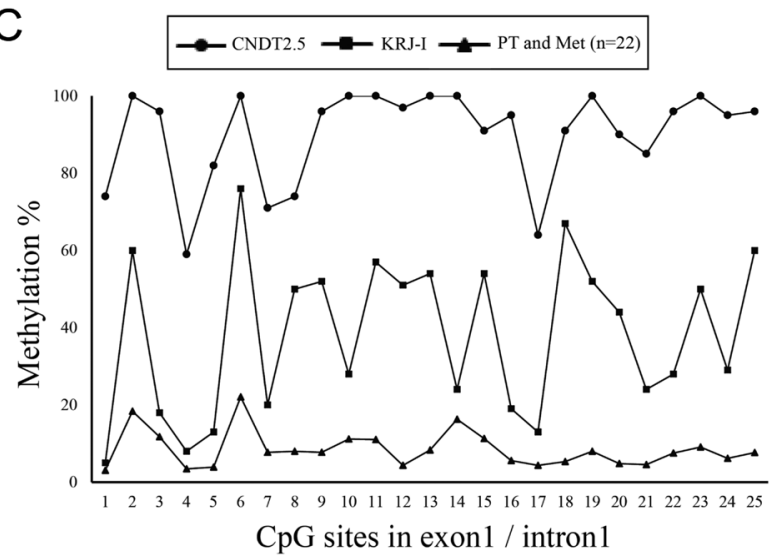

Figure 5

Quantitative bisulfite pyrosequencing analysis of the PTPRM gene. (A) Schematic structure of the PTPRM gene upstream regulatory region and exon 1. Location of CGI, CGI shores and DNA methylation assays are shown. (B) Methylation analysis of $13 \mathrm{CpG}$ residues in the promoter region. (C) Methylation analysis of $25 \mathrm{CpG}$ residues at the exon1/intron 1 region.

in 20 primary tumors and metastases, and 3 small intestinal tissue specimens. Our result showed (Supplementary Fig. 3A, B and Supplementary Table 4) that these CpG sites were methylated in all tissue specimens analyzed, and in the two SI-NET cell lines. The CpG site \# 3 in shore 2 was found to be significantly more methylated in the SI-NETs compared to small intestine tissues $(P=0.000)$ (Supplementary Fig. 3A and Supplementary Table 4). Taken together, these results suggest that $\mathrm{CpG}$ methylations at the investigated regions of PTPRM could be involved in repressing PTPRM expression in the two

https://ec.bioscientifica.com https://doi.org/10.1530/EC-19-0279 (c) 2019 The authors Published by Bioscientifica Ltd
This work is licensed under a Creative Commons Attribution-NonCommercial-NoDerivatives 4.0 enternationab ticense.ifica.com at 04/26/2023 09:11:33AM 
SI-NET cell lines. However, in the analyzed tumors, other epigenetic mechanisms rather than promoter hypermethylation could be involved. The global histone methyltransferase inhibitor DZNep induced expression of PTPRM in the SI-NET cell lines suggesting a possible involvement of histone methyltransferases.

\section{A growth regulatory role of PTPRM in SI-NET cells}

To establish whether PTPRM located on chromosome 18 could be involved in the regulation of cellular growth control and then potentially could play a role in small intestinal neuroendocrine tumorigenesis, a cell colony formation assay was performed. An expression vector encoding PTPRM was transfected to the SI-NET cell line CNDT2.5 followed by puromycin selection of expressing cells. As shown in Fig. 6A, overexpression of PTPRM resulted in reduced number of cell colonies compared to control transfected cells. In line with these results, cell proliferation was also reduced in PTPRM-expressing cells compared to empty vector transfected cells, as observed in both CNDT2.5 and KRJ-I cells (Fig. 6B). Under these conditions, apoptosis, as determined by quantifying cytoplasmic histone-associated-DNA-fragments, was detected (Fig. 6B). Successful expression of PTPRM after transfection was monitored by quantitative RT-PCR and immunoprecipitation followed by Western blotting analysis (Supplementary Fig. 4A and B). We also determined the expression of the puromycin- $\mathrm{N}$-acetyltransferase gene (pac) from the empty expression vector (pEnter) and the PTPRM expression vector. No significant difference in expression of the pac gene was observed $(P=0.1)$ supporting similar transfection efficiencies for the two different plasmids (Supplementary Fig. 4C). These results supported a cell growth regulatory role for PTPRM in SI-NET cells.

\section{The phosphatase activity of PTPRM is not involved in cell growth inhibition}

In order to investigate whether the phosphatase activity of PTPRM was necessary for cell growth inhibition, a double mutant of PTPRM in which the Cys ${ }^{1095}$ and Cys ${ }^{1389}$ residues were changed to serine to disrupt phosphatase activity (11), was analyzed by the cell colony formation assay. Both PTPRM-wt and PTPRM-mut showed the same growth inhibiting activity (Fig. 7A), suggesting that the phosphatase activity was not involved in cell growth inhibition.
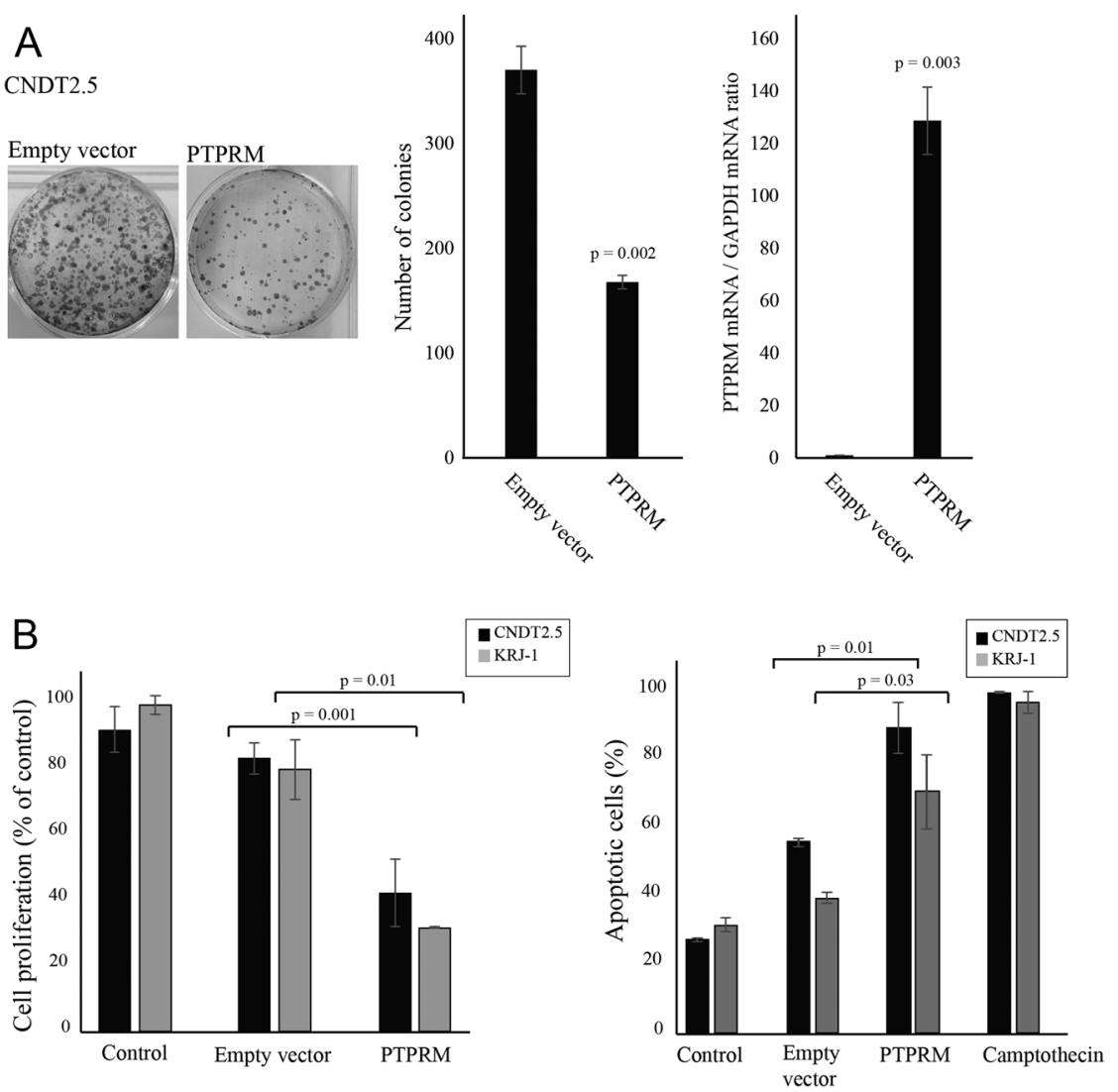

Figure 6

Growth regulatory role of PTPRM in SI-NET cells. (A) Colony formation assay in the adhesive CNDT2.5 cell line. Cells transfected with PTPRM expression vector or an empty vector were selected for puromycin resistance, and colonies were counted after 10 days. Increased expression of PTPRM was measured at mRNA level after transfection. (B) Determination of cell proliferation and apoptosis in CNDT2.5 (adhesive cells) and KRJ-I (suspension cells) transfected with PTPRM expression vector or empty vector for $72 \mathrm{~h}$. Data shown are means \pm s.D. of triplicates. https://ec.bioscientifica.com https://doi.org/10.1530/EC-19-0279 (c) 2019 The authors Published by Bioscientifica Ltd

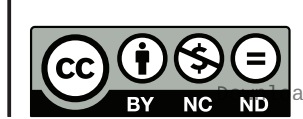

This work is licensed under a Creative Commons Attribution-NonCommercial-NoDerivatives 4.0 Internationad ticense ifica.com at 04/26/2023 09:11:33AM 

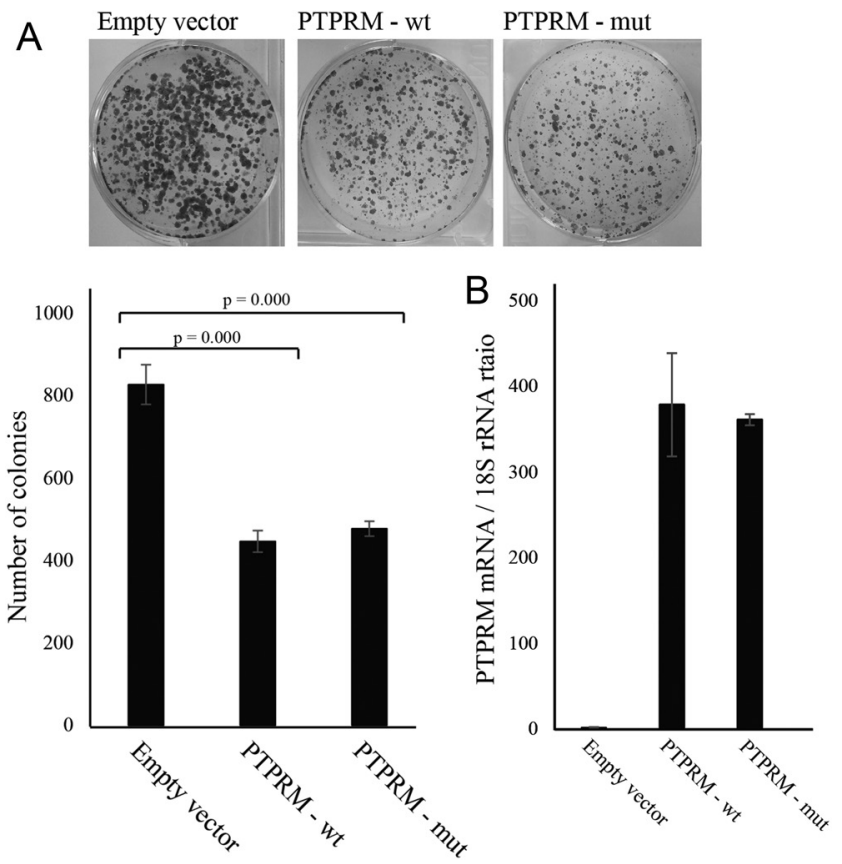

\section{Figure 7}

Expression of both PTPRM-wt and PTPRM-mut suppresses colony formation in SI-NET cells. (A) CNDT2.5 cells transfected with empty vector PTPRM-wt or PTPRM-mut were selected for G418 resistance and colonies were counted after 10 days. PTPRM-mut consisted of a double mutant of PTPRM in which the Cys ${ }^{1095}$ and $\mathrm{Cys}^{1389}$ residues were changed to serine in order to disrupt tyrosine phosphatase activity (11). (B) Expression of PTPRM after transfection as determined by quantitative real-time RT-PCR (ANOVA and Bonferroni test were applied). Data shown are means \pm s.D. of triplicates. Note that the expression plasmid PTPRM-wt was different from the one used in the experiment of Fig. 6.

Successful expression of PTPRM WT and mutant were monitored by RT-PCR (Fig. 7B).

\section{Discussion}

Previous studies demonstrated SI-NETs as stable tumors with no highly recurrent mutations, but epigenetically dysregulated. Loss of one copy of chromosome 18 is the most frequent aberration in primary and metastatic SI-NETs; however, genetic and genomic approaches failed to identify a mutated tumor suppressor gene on chromosome 18. Examining epigenetic mechanisms in this region may allow identification of candidate genes responsible for initiation and progression of SI-NETs. In this study, we investigated expression level and function of PTPRM located on 18p11.2 in SI-NETs followed by methylation profile evaluation to identify a possible role of PTPRM in SI-NETs tumorigenesis.
Protein tyrosine phosphatases (PTPs) are important regulators of signaling pathways involved in cell proliferation, adhesion and migration, and perturbation of PTPs activity is associated with tumorigenesis of various types of human cancer $(21,22)$. In human prostate carcinoma cells, lack of PTPRM expression was associated with loss of PTPRM- or E-cadherin-dependent cell adhesion, and in breast cancer cells, was associated with poor prognosis and increased cell proliferation and invasion, suggesting a role of PTPRM as a tumor suppressor $(23,24)$. Our analysis by immunohistochemistry demonstrated undetectable/very low level of PTPRM or aberrant pattern of staining, with both negative and positive areas, in the majority of analyzed tumors (33/40). Cytoplasmic or cytoplasmic/nuclear localization of PTPRM was observed in tumors with either VH or positive pattern of staining. Nuclear localization of PTPRM has been previously reported in glioma cells, where proteolysis of PTPRM resulted in several extracellular and intracellular fragments, and the intracellular fragment produced by gamma secretase was capable of translocating to the nucleus $(25,26,27)$. Whether this occurs in SI-NETs awaits further studies. Significantly reduced mRNA level of PTPRM in metastases compared to primary tumors further supported a role as tumor suppressor gene in SI-NETs. Furthermore, gene expression profiles of SI-NETs by RNA-seq analysis revealed reduced PTPRM mRNA expression in tumors with one copy of chromosome 18 compared to tumors with two gene copies (S. Backman, personal communication).

Both CNDT2.5 and KRJ-I cells used in this study express very low levels of endogenous PTPRM and our data that PTPRM overexpression in vitro reduced cell proliferation and induced apoptosis suggest a tumor-suppressive role of PTPRM in SI-NET cells. We found that expression of both WT and mutant form of PTPRM decreased number of colonies and suppressed cell growth, suggesting that perturbation of the phosphatase activity did not alter PTPRM-mediated growth regulation, as also demonstrated in previous studies of other tumor types $(11,23)$.

Previous studies have reported PTPRM inactivation through exon 1/intron 1 DNA methylation and loss of heterozygosity in colorectal cancer $(11,28)$. However, bisulfite pyrosequencing showed no methylation in SI-NETs in the promoter or in the exon 1/intron 1 region, although methylation was clearly detected in both SI-NET cell lines. We further investigated DNA methylation levels in the presumed CGI shores upstream of the PTPRM gene. In this part of the gene, all investigated tissue

This work is licensed under a Creative Commons Attribution-NonCommercial-NoDerivatives 4.0 Internationab ticense.ifica com at $04 / 26 / 2023 \quad 09: 11: 33 \mathrm{Am}$ 
specimens and the two SI-NET cell lines showed high and variable methylation levels. Interestingly and in line with a published report (7), the CpG site \# 3 in shore 2 was found to be significantly more methylated in the SI-NETs compared to the small intestine tissues. It should be noted that 'small intestine tissues' have been used arbitrary as 'normal tissue' instead of the difficult to enrich and purify enterochromaffin cells of the small intestine. Both the DNA methylation inhibitor 5-aza-2'-deoxycytidine and the global histone methyltransferase inhibitor DZNep induced expression of PTPRM in CNDT2.5 and KRJ-I cells, suggesting that PTPRM expression can be controlled by epigenetic mechanisms in SI-NET cells and that it will be of future interest to investigate the effect of histone methyltransferases on PTPRM expression. Taken together, the results support a role for PTPRM as a dysregulated candidate tumor suppressor gene in SI-NETs. The effects of inactivated PTPRM on cell-cell adhesion and signaling pathways also warrant further investigation.

\section{Supplementary data}

This is linked to the online version of the paper at https://doi.org/10.1530/ EC-19-0279.

\section{Declaration of interest}

The authors declare that there is no conflict of interest that could be perceived as prejudicing the impartiality of the research reported.

\section{Funding}

This work was supported by grants from The Swedish Cancer Society, Lions Fund for Cancer Research, Erik, Karin o Gösta Selanders Stiftelse and governmental funding of clinical research within the Swedish National Health Service (ALF).

\section{Author contribution statement}

$\mathrm{G}$ W and P S contributed equally to this work.

\section{Acknowledgements}

The authors are grateful to Birgitta Bondeson for skillful technical assistance. The authors thank Dr Joanne Jeou-Yuan Chen for making the expression vectors PTPRM-wt and PTPRM-mut available to us.

\section{References}

1 Banck MS, Kanwar R, Kulkarni AA, Boora GK, Metge F, Kipp BR, Zhang L, Thorland EC, Minn KT, Tentu R, et al. The genomic landscape of small intestine neuroendocrine tumors. Journal of Clinical Investigation 2013123 2502-2508. (https://doi.org/10.1172/JCI67963)

2 Stalberg P, Westin G \& Thirlwell C. Genetics and epigenetics in small intestinal neuroendocrine tumours. Journal of Internal Medicine 2016 280 584-594. (https://doi.org/10.1111/joim.12526)
3 Di Domenico A, Wiedmer T, Marinoni I \& Perren A. Genetic and epigenetic drivers of neuroendocrine tumours (NET). Endocrine-Related Cancer 201724 R315-R334. (https://doi.org/10.1530/ERC-17-0012)

4 Francis JM, Kiezun A, Ramos AH, Serra S, Pedamallu CS, Qian ZR, Banck MS, Kanwar R, Kulkarni AA, Karpathakis A, et al. Somatic mutation of CDKN1B in small intestine neuroendocrine tumors. Nature Genetics 201345 1483-1486. (https://doi.org/10.1038/ng.2821)

5 Zhang HY, Rumilla KM, Jin L, Nakamura N, Stilling GA, Ruebel KH, Hobday TJ, Erlichman C, Erickson LA \& Lloyd RV. Association of DNA methylation and epigenetic inactivation of RASSF1A and betacatenin with metastasis in small bowel carcinoid tumors. Endocrine 200630 299-306. (https://doi.org/10.1007/s12020-006-0008-1) 6 Edfeldt K, Ahmad T, Akerstrom G, Janson ET, Hellman P, Stalberg P, Bjorklund P \& Westin G. TCEB3C a putative tumor suppressor gene of small intestinal neuroendocrine tumors. Endocrine-Related Cancer 201421 275-284. (https://doi.org/10.1530/ERC-13-0419)

7 Karpathakis A, Dibra H, Pipinikas C, Feber A, Morris T, Francis J, Oukrif D, Mandair D, Pericleous M, Mohmaduvesh M, et al. Prognostic impact of novel molecular subtypes of small intestinal neuroendocrine tumor. Clinical Cancer Research 201622 250-258. (https://doi.org/10.1158/1078-0432.CCR-15-0373)

8 Verdugo AD, Crona J, Starker L, Stalberg P, Akerstrom G, Westin G, Hellman P \& Bjorklund P. Global DNA methylation patterns through an array-based approach in small intestinal neuroendocrine tumors. Endocrine-Related Cancer 201421 L5-L7. (https://doi.org/10.1530/ ERC-13-0481)

9 Fotouhi O, Adel Fahmideh M, Kjellman M, Sulaiman L, Hoog A, Zedenius J, Hashemi J \& Larsson C. Global hypomethylation and promoter methylation in small intestinal neuroendocrine tumors: an in vivo and in vitro study. Epigenetics 20149 987-997. (https://doi. org/10.4161/epi.28936)

10 Stevenson WS, Best OG, Przybylla A, Chen Q, Singh N, Koleth M, Pierce S, Kennedy T, Tong W, Kuang SQ et al. DNA methylation of membrane-bound tyrosine phosphatase genes in acute lymphoblastic leukaemia. Leukemia 201428 787-793. (https://doi.org/10.1038/ leu.2013.270)

11 Sudhir PR, Lin ST, Chia-Wen C, Yang SH, Li AF, Lai RH, Wang MJ, Chen YT, Chen CF, Jou YS, et al. Loss of PTPRM associates with the pathogenic development of colorectal adenoma-carcinoma sequence. Scientific Reports 20155 9633. (https://doi.org/10.1038/srep09633)

12 Laczmanska I, Karpinski P, Bebenek M, Sedziak T, Ramsey D, Szmida E \& Sasiadek MM. Protein tyrosine phosphatase receptor-like genes are frequently hypermethylated in sporadic colorectal cancer. Journal of Human Genetics 201358 11-15. (https://doi.org/10.1038/ jhg.2012.119)

13 Hyun SW, Anglin IE, Liu A, Yang S, Sorkin JD, Lillehoj E, Tonks NK, Passaniti A \& Goldblum SE. Diverse injurious stimuli reduce protein tyrosine phosphatase-mu expression and enhance epidermal growth factor receptor signaling in human airway epithelia. Experimental Lung Research 201137 327-343. (https://doi.org/10.3109/01902148.2 $011.566673)$

14 Burgoyne AM, Palomo JM, Phillips-Mason PJ, Burden-Gulley SM, Major DL, Zaremba A, Robinson S, Sloan AE, Vogelbaum MA, Miller RH, et al. PTPmu suppresses glioma cell migration and dispersal. Neuro-Oncology 200911 767-778. (https://doi. org/10.1215/15228517-2009-019)

15 Van Buren 2nd G, Rashid A, Yang AD, Abdalla EK, Gray MJ, Liu W, Somcio R, Fan F, Camp ER, Yao JC, et al. The development and characterization of a human midgut carcinoid cell line. Clinical Cancer Research 200713 4704-4712. (https://doi.org/10.1158/10780432.CCR-06-2723)

16 Li SC, Martijn C, Cui T, Essaghir A, Luque RM, Demoulin JB, Castano JP, Oberg K \& Giandomenico V. The somatostatin analogue octreotide inhibits growth of small intestine neuroendocrine tumour cells. PLoS ONE 20127 e48411. (https://doi.org/10.1371/journal. pone.0048411) 
17 Ellis LM, Samuel S \& Sceusi E. Varying opinions on the authenticity of a human midgut carcinoid cell line - letter. Clinical Cancer Research 201016 5365-5366. (https://doi.org/10.1158/1078-0432.CCR-10-2550)

18 Pfragner R, Wirnsberger G, Niederle B, Behmel A, Rinner I, Mandl A, Wawrina F, Luo J, Adamiker D, Hoger H, et al. Establishment of a continuous cell line from a human carcinoid of the small intestine (KRJ-I). International Journal of Oncology 19968 513-520. (https://doi. org/10.3892/ijo.8.3.513)

19 Modlin IM, Kidd M, Pfragner R, Eick GN \& Champaneria MC. The functional characterization of normal and neoplastic human enterochromaffin cells. Journal of Clinical Endocrinology and Metabolism 200691 2340-2348. (https://doi.org/10.1210/jc.2006-0110)

20 Barazeghi E, Prabhawa S, Norlen O, Hellman P, Stalberg P \& Westin G. Decrease of 5-hydroxymethylcytosine and TET1 with nuclear exclusion of TET2 in small intestinal neuroendocrine tumors. BMC Cancer 201818 764. (https://doi.org/10.1186/s12885-018-4579-z)

21 Ostman A, Hellberg C \& Bohmer FD. Protein-tyrosine phosphatases and cancer. Nature Reviews: Cancer 20066 307-320. (https://doi. org/10.1038/nrc1837)

22 Tonks NK. Protein tyrosine phosphatases: from genes, to function, to disease. Nature Reviews: Molecular Cell Biology 20067 833-846. (https://doi.org/10.1038/nrm2039)

23 Hellberg CB, Burden-Gulley SM, Pietz GE \& Brady-Kalnay SM. Expression of the receptor protein-tyrosine phosphatase, PTPmu, restores E-cadherin-dependent adhesion in human prostate carcinoma cells. Journal of Biological Chemistry 2002277 11165-11173. (https://doi.org/10.1074/jbc.M112157200)
24 Sun PH, Ye L, Mason MD \& Jiang WG. Protein tyrosine phosphatase micro (PTP micro or PTPRM), a negative regulator of proliferation and invasion of breast cancer cells, is associated with disease prognosis. PLoS ONE 20127 e50183. (https://doi.org/10.1371/ journal.pone.0050183)

25 Anders L, Mertins P, Lammich S, Murgia M, Hartmann D, Saftig P, Haass C \& Ullrich A. Furin-, ADAM 10-, and gamma-secretasemediated cleavage of a receptor tyrosine phosphatase and regulation of beta-catenin's transcriptional activity. Molecular and Cellular Biology 200626 3917-3934. (https://doi.org/10.1128/ MCB.26.10.3917-3934.2006)

26 Burgoyne AM, Phillips-Mason PJ, Burden-Gulley SM, Robinson S, Sloan AE, Miller RH \& Brady-Kalnay SM. Proteolytic cleavage of protein tyrosine phosphatase mu regulates glioblastoma cell migration. Cancer Research 200969 6960-6968. (https://doi. org/10.1158/0008-5472.CAN-09-0863)

27 Phillips-Mason PJ, Craig SE \& Brady-Kalnay SM. A protease storm cleaves a cell-cell adhesion molecule in cancer: multiple proteases converge to regulate PTPmu in glioma cells. Journal of Cellular Biochemistry 2014115 1609-1623. (https://doi.org/10.1002/ jcb.24824)

28 Laczmanska I, Karpinski P, Kozlowska J, Bebenek M, Ramsey D, Sedziak T, Ziolkowski P \& Sasiadek MM. Copy number alterations of chromosomal regions enclosing protein tyrosine phosphatase receptor-like genes in colorectal cancer. Pathology, Research and Practice 2014210 893-896. (https://doi.org/10.1016/j. prp.2014.07.010)

Received in final form 26 June 2019

Accepted 9 July 2019

Accepted Preprint published online 9 July 2019 https://ec.bioscientifica.com https://doi.org/10.1530/EC-19-0279 (c) 2019 The authors Published by Bioscientifica Ltd
This work is licensed under a Creative Commons Attribution-NonCommercial-NoDerivatives 4.0

Internationab License. ifica com at 04/26/2023 09:11:33AM 